\title{
Patient Safety Incident Reporting In Indonesia: An Analysis Using World Health Organization Characteristics For Successful Reporting
}

This article was published in the following Dove Press journal: Risk Management and Healthcare Policy

\author{
Inge Dhamanti $\mathbb{D}^{1-3}$ \\ Sandra Leggat $\mathbb{1}^{3}$ \\ Simon Barraclough ${ }^{3}$ \\ Benny Tjahjono $\mathbb{D}^{4}$
}

'Department of Health Policy and Administration, Faculty of Public Health, Universitas Airlangga, Surabaya, Indonesia; ${ }^{2}$ Center for Patient Safety Research, Universitas Airlangga, Surabaya, Indonesia; ${ }^{3}$ School of Psychology and Public Health, La Trobe University, Melbourne, VIC, Australia; ${ }^{4}$ Centre for Business in Society, Coventry University, Coventry, UK
Correspondence: Inge Dhamanti Department of Health Policy and Administration, Faculty of Public Health, Universitas Airlangga, Surabaya, Indonesia Email inge-d@fkm.unair.ac.id
Background: Incident reporting is widely acknowledged as one of the ways of improving patient safety and has been implemented in Indonesia for more than ten years. However, there was no significant increase in the number of reported incidents nationally. The study described in this paper aimed at assessing the extent to which Indonesia's patient safety incident reporting system has adhered to the World Health Organization (WHO) characteristics for successful reporting.

Methods: We interviewed officials from 16 organizations at national, provincial and district or city levels in Indonesia. We reviewed several policies, guidelines and regulations pertinent to incident reporting in Indonesia and examined whether the WHO characteristics were covered in these documents. We used NVivo version 9 to manage the interview data and applied thematic analysis to organize our findings.

Results: Our study found that there was an increased need for a non-punitive system, confidentiality, expert-analysis and timeliness of reporting, system-orientation and responsiveness. The existing guidelines, policies and regulations in Indonesia, to a large extent, have not satisfied all the required WHO characteristics of incident reporting. Furthermore, awareness and understanding of the reporting system amongst officials at almost all levels were lacking.

Conclusion: Despite being implemented for more than a decade, Indonesia's patient safety incident reporting system has not fully adhered to the WHO guidelines. There is a pressing need for the Indonesian Government to improve the system, by putting specific regulations and by creating a robust infrastructure at all levels to support the incident reporting.

Keywords: patient safety, incident reporting, WHO guidelines

\section{Introduction}

Incident reporting is widely acknowledged as one of the ways of improving patient safety. ${ }^{1}$ Incident reporting systems have been established in many countries such as Malaysia, Taiwan, Japan, United Kingdom, Denmark, Canada, United States, Netherland and Germany. ${ }^{2-6}$ The WHO Patient Safety Program was established in 2004 to facilitate and accelerate the international effort on patient safety. WHO developed several implementation guides to assist countries in creating incident reporting systems or to improve patient safety in general. These guides include the Draft Guidelines for Adverse Events Reporting and Learning System, ${ }^{7}$ the Conceptual Framework for the International Classification for Patient Safety, ${ }^{8}$ the Surgical Safety Check-list ${ }^{9}$ or the Safe Childbirth Checklist. ${ }^{10}$ 
In Indonesia, the incident reporting system was first introduced in 2006 along with the Government's published guidelines ${ }^{10-12}$ to support its implementation. The Indonesian government authorizes the management and implementation of the national patient safety and incident reporting to three independent organizations, i.e. the National Committee on Hospital Patient Safety (the National Committee), the Indonesian Hospital Association (IHA) and the Hospital Accreditation Commission (HAC). The Government also published various related regulations ${ }^{13,14}$ of which the most recent ones stipulate that every health facility, whether accredited or not, should have implemented a patient safety program incorporating the incident reporting system. ${ }^{14}$

The incident reporting system in Indonesia is split into internal and external systems. ${ }^{12}$ The internal reporting system is usually paper-based and operates at the hospital levels. Anyone who has experienced or witnessed an incident shall submit a report to the supervisor or the head of the unit who then assesses the incident and determines its grade for the purpose of conducting either comprehensive or simple investigation. Adverse or sentinel events need thorough investigation using Root Cause Analysis that typically takes between 14 and 45 days. The completed reports are then sent to the National Committee as an external report.

At the hospital level, the implementation of incident reporting systems varies. Hospitals, traditionally, have had poor reporting culture signified by the health care workers did not report incidents, despite having been involved in or witnessing incidents. Moreover, follow-on investigations were not conducted properly and there was a lack of feedback and systematic learning. ${ }^{15-18}$ At the national level, there were only 132 reported incidents in $2013^{17}$ though it increased to 688 in 2016, according to recent data. ${ }^{19}$ At this level, the performance data are also more difficult to assess because annual reports, evaluation or comprehensive websites dedicated to the incident reporting or patient safety shared to the public are not publicly available.

The purpose of this study is to explore the extent to which the Indonesian incident reporting system has adhered to the WHO characteristics for successful reporting. To the best of our knowledge, this study is the first of its kind that analyzes the Indonesia's health care system using the WHO characteristics (summarized in Table 1) and reports the views of officials from various bodies comprising government organizations, independent institutions and professional organizations at the central, provincial or regional, district or city and public hospital levels.

\section{Methods}

\section{Study Design And Setting}

This study employed a descriptive qualitative approach whose data collection method involved interviews and reviews of the policies and regulations concerning patient safety incident reporting in Indonesia conducted between 2013 and 2016.

\section{Interview}

The informants were chosen purposively from the organizations involved in patient safety implementation at the national, provincial and district or city levels in Indonesia.

Table I WHO Characteristics For A Successful Patient Safety Incident Reporting System

\begin{tabular}{|c|c|}
\hline Characteristic & Definition \\
\hline Non-punitive & Reporters are free from fear of retaliation against themselves or punishment of others because of reporting. \\
\hline Confidential & The identities of the patient, reporter and institution are never revealed. \\
\hline Independence & $\begin{array}{l}\text { The reporting system is independent of any authority with power to punish the reporter or the organization for example by } \\
\text { maintaining a "firewall" between the reporting agency and the disciplinary agency in a governmental system. }\end{array}$ \\
\hline Expert analysis & Reports are evaluated by experts who understand the clinical circumstances and are trained to recognize underlying systems cause. \\
\hline Timely & $\begin{array}{l}\text { Reports are analyzed promptly and recommendations are rapidly disseminated to those who need to know, especially when } \\
\text { serious hazards are identified. }\end{array}$ \\
\hline System-oriented & Recommendations focus on changes in systems, processes or products, rather than being targeted at individual performance. \\
\hline Responsive & $\begin{array}{l}\text { The agency that receives reports is capable of disseminating recommendations. Participating organizations commit to } \\
\text { implementing recommendations whenever possible. }\end{array}$ \\
\hline
\end{tabular}

Notes: Reproduced from WHO Draft Guidelines for Adverse Event Reporting and Learning Systems, WHO, Copyright 2005. ${ }^{7}$ 
We identified potential interviewees using publicly available information or by requesting the organization to nominate officials involved in patient safety or handle the patient safety program in their organizations. We sent the letters to the 34 informants from 16 targeted organizations (see Table 2), requesting their participation. All but one agreed to participate. Within each district or city, the first author interviewed officials from the Department of Health Office (DHO) and an accredited public hospital.

We developed semi-structured interview questions reflecting the WHO characteristics of a successful patient safety incident reporting system. The interview protocol was sent to informants before the interview. After obtaining the consent, the first interviews took place at the informants' offices. The interviews were conducted in Indonesian, lasted between $40 \mathrm{mins}$ and an hour and were voice-recorded. During the interviews, notes were also taken to supplement the interview scripts.

\section{Reviews Of The Policies And Regulations}

We identified several policies, guidelines and regulations related to incident reporting in Indonesia ${ }^{11-14}$ and examined whether the WHO characteristics were covered in these documents.

\section{Data Analysis}

The recorded interviews were transcribed, translated into English and checked for accuracy by a bi-lingual third party. We used NVivo version 9 to manage the interview data. To ensure confidentiality, individuals were not identified, although the name of their organizations and locations were reported. A priori codes were derived from the research questions and the WHO characteristics for successful reporting. We also identified several emerging (post hoc) codes from the interviews. The first author carried out the coding process and the second author reviewed the coding lists.

We applied thematic analysis, a systematic procedure for identifying, analyzing and interpreting themes within the qualitative data. ${ }^{20}$ The whole process in thematic analysis includes identification of themes in the literature, summarizing the findings under thematic headings and comparing, contrasting and connecting the findings from all sources. ${ }^{21}$

\section{Ethics Approval}

Ethics approval was obtained from the Faculty of Health Sciences Human Research Ethics Committee, La Trobe University application number FHEC13/197 as well as the institutional approvals from the participating organizations.

\section{Results \\ Non-Punitive Approach}

The interview data revealed the continuation of a punitive environment related to incident reporting in hospital level, professional organization and at the national level. According to the informants, hospital-imposed sanctions on staff were in the forms of "disciplinary proceedings", "technical supervision", "notice and warning", "verbal or written

Table 2 List Of Organizations And The Number Of Informants

\begin{tabular}{|l|l|}
\hline Organizations & Number Of Informants \\
\hline $\begin{array}{l}\text { Government organizations } \\
\text { Indonesian Ministry of Health (IMoH) }\end{array}$ & 2 \\
$\begin{array}{l}\text { Provincial Health Office D (PHO) } \\
\text { District Health Offices at District/City A, B and C (DHO) }\end{array}$ & 2 \\
\hline $\begin{array}{l}\text { Independent institutions } \\
\text { National Committee on Hospital Patient Safety (the National Committee) } \\
\text { Commission for Hospital Accreditation (CHA) } \\
\text { Indonesian Hospital Association (IHA) at the national and provincial levels }\end{array}$ & 5 \\
\hline $\begin{array}{l}\text { Professional organizations } \\
\text { Indonesian Medical Association (IMA) at national and provincial level } \\
\text { Indonesian National Nurses Association (INA) at national and provincial level }\end{array}$ & 2 \\
\hline $\begin{array}{l}\text { Public hospitals } \\
\text { Public hospital at District/City A, B and C (Hospital A, B and C) }\end{array}$ & 3 \\
\hline Total & 4 \\
\hline
\end{tabular}


warning" and in one case, "termination" of employment, as an informant reported:

The non-punitive culture may not be $100 \%$ implemented at both local and national levels. Sometimes there was a conflict of interest, especially related to the Human Resource Department as they need to give some disciplinary sanctions to staff [even though this goes] against the non-punitive culture in patient safety. (IHA, provincial level)

A punitive culture within a professional organization was also identified:

We will clarify [the case] by calling in the doctor involved ... If they were wrong, then we blamed them ... If it was a police matter, then if it is possible, we have to defend them. (IMA, national level)

At the national level, an informant argued that identifying hospitals where incidents had occurred, in the context of national patient safety seminars and workshops, could be regarded as punitive.

\section{Confidentiality}

The two levels of confidentiality in the patient safety incident reporting system were the hospital-level reporting (internal reporting) and the national-level reporting (external reporting). Those reporting internally were required to provide their names, and sign the forms; and they are prohibited from copying the forms for any reason. ${ }^{14}$ In external reporting, a hospital's name did not need to be identified; however, the hospital code had to be included. ${ }^{12}$ Some informants considered this kind of reporting system not confidential:

The reporting in hospital[s] was not confidential because the staff should not copy the forms, but I saw some of them did so. (CHA, national level)

The problem within this confidentiality: there was no guarantee or certainty that [the data] will not be open to [the] public or for other interested parties. Maybe the National Committee had put efforts on this, but the reporter still felt uncertain. (IHA, provincial level)

\section{Independence}

The reporting system must be free from any disciplinary actions against reporters or the organization. ${ }^{7}$ All those interviewed agreed that the reporting system was independent, as an informant stated:
I think our reporting system was independent since it was free from any intervention by individuals or the hospital management. (IHA, provincial level)

\section{Expert Analysis}

It is recommended by WHO that experts or people that understand the clinical conditions and are trained to analyze the systematic cause of incidents are included in the incident report analysis. ${ }^{7}$ The interview data showed that most informants thought hospitals had involved experts in the analysis of incident reports. Typical of this view was the observation of an informant:

The meaning of experts is the people were trained, right? I think we have done that. (CHA, national level)

However, another commented:

I thought we have not done that $\ldots$ because the number of medical specialists in Indonesia was limited. Maybe the experts only analyze [the incident] in big centers but, for regional cases which had no medical specialist or sub-specialist, we still lack analysis from them. (IHA, provincial level)

\section{Timeliness}

In the internal reporting system, the timeline for reporting is typically within $48 \mathrm{hrs}$, and the investigation should take place between 7 and 45 days, depending on the type of analysis. ${ }^{12}$ Most informants agreed that the reporting system was not timely as is exemplified in the following comments:

There was no timeline in the reporting. Within internal reporting, it was 24 hours, but there was no timeline in national reporting. (CHA, national level)

In our culture, the bureaucratic system is lengthy so [the reporting] is never on time. The reporting sometimes has to go [to many levels] from the bottom level to the head of unit, directors, etc. Therefore, I think we have not achieved that. (IHA, provincial level)

\section{System-Oriented}

Most informants felt that the reporting system was systemoriented but needed improvement. Typical comments were:

Sometimes we could not be $100 \%$ system-oriented because the people within the system often focused on human factors [instead of the system]. (IHA, provincial level)

We are not system-oriented yet because we did not improve the system. (IMoH, national level) 


\section{Responsiveness}

Responsiveness was related to the capability of the organization that received the reports to create and disseminate recommendations while also targeting organizations to make a commitment to implement recommendations. ${ }^{7}$ The informant from the National Committee considered that the system was responsive:

Yes, our system was responsive. We were not involved in solving the problem [in hospitals] but we provided the feedback through a learning process. (the National Committee, national level)

However, most informants felt that the National Committee, as the organization that handled and received the reports, was not responsive, as these extracts from the interviews illustrate:

There was no feedback given to the hospitals that reported the incidents. (IHA, national level)

At the hospital level, there were many barriers; for example, whether the hospital management was responsive enough in sending the report to the national level. In addition, we have to see whether the organization that received the reports [the National Committee] was responsive and provided direct feedback [to the hospitals]. I was not sure about that. (IHA, provincial level)

\section{Policy Review}

The IMoH regulations stipulate the need for a non-punitive approach in several places (for example, in the Articles 16 and 19) and specify it as one of the seven steps to patient safety. ${ }^{14}$ Confidentiality, anonymity and security are covered in Articles 19 and 23; however, in Article 19, it is unclear whose identity should be anonymous. ${ }^{17}$ In contrast, in Article 23, it is clearly stated that for an adverse event with a wide or national-scale impact, the identity of both patient and health care personnel must be anonymous. Confidentiality is also mentioned in two other regulations, including as the roles of National Committee and in Article 43 as the goal of incident reporting. ${ }^{15,16}$

As part of the fifth step to patient safety, ${ }^{14}$ timelines are critical. Timeliness in reporting was stated in Article 23. For adverse events with a wide or national-level impact, incidents must be reported within one hour. ${ }^{14}$ Timeliness were also mentioned in the national guidelines where the report needs to be submitted within a certain period of time, though the exact time was not specified. ${ }^{11}$ The need of a system-oriented approach was described in Article 43, in which providing feedback has been part of responsiveness specified in the national guidelines ${ }^{12,13}$ and in the seventh step to incident reporting. ${ }^{14}$ However, the requirements for independence and expert analysis have not been covered in the policies reviewed.

\section{Discussion}

Eight important findings were revealed from this study. First, a punitive culture persists at both the hospital and national levels. These findings are consistent with other research in Indonesia reporting the prevalence of a punitive culture. ${ }^{16,22-26}$ This is, unfortunately, inconsistent with best practice incident reporting, which should not result in reprimands or sanctions if systemic issues are involved. ${ }^{7}$

Second, there were problems with the confidentiality and security of the reporting system, e.g. copying incident forms at the hospitals and identifying the hospitals in seminars and patient safety training sessions. In order to maintain confidentiality of the system, the organizations, the patients and the reporter must be guaranteed; such information must never be revealed to a third party. ${ }^{5,7}$

As in the case of confidentiality, some informants still doubted the security of the system. As the incident report may contain information allowing for the identification of people involved, removing such information and making the report anonymous is important. ${ }^{27}$ Data security needs to be enhanced to avoid unauthorized access.

Third, all informants believed that the Indonesian incident reporting system was independent and free from any intervention by individuals or other organizations. For example, there is a separation in roles between the reporting agency which is handled by the National Committee and the disciplinary agencies, such as the Indonesian Medical Disciplinary Board. The Board is an autonomous body of the Indonesian Medical Council, which determines whether any misconduct or neglect has occurred in medical practice while also ensuring that the sanctions imposed are appropriate and proportional. ${ }^{28}$

Fourth, there are several differing views on whether the incident analysis in Indonesia should involve an expert analysis. The informant's understanding of the term "expert" also varied. Significantly, the term "expert" was not found in the incident reporting guidelines. Another study in three public hospitals in Indonesia revealed that the comprehensive incident investigation had not been carried out and that some incidents were not properly analyzed. ${ }^{17}$ Expertise is an essential resource required for analyzing any incident in any reporting system. The expert 
could be someone from within the organization or from an external organization capable of providing an independent advice. $^{29}$

Fifth, timeliness in reporting is a significant issue in incident reporting in Indonesia. There is a timeline for internal reporting; however, no timeline has been established for external reporting. ${ }^{12,17}$ Reports should be reviewed without delay. The learning and actions for improvement, as well as the recommendations, should be promptly disseminated to those who reported in the first place, to the rest of the system and to the wider society. ${ }^{30}$ The timeline for a solution to be implemented needs to be clearly stated. Furthermore, the effectiveness of the solution also needs to be monitored and evaluated at the organization level. ${ }^{31}$ When a serious hazard occurs, an immediate notification should take place to the wider setting to prevent any further harm. ${ }^{27}$

Sixth, most informants reported that those who developed the reporting system had attempted to adopt a system-oriented approach, but a significant improvement is still needed. Within a system-oriented perspective, it is postulated that incidents occur not because of individual's mistakes but rather were caused by system's failures. It is a major challenge for reporting to be system-oriented since, as discussed previously, a blaming culture prevails at almost all levels.

Seventh, with regard to the responsiveness of the system, most informants considered that there was a need for improvement. The local level of reporting seemed to focus on learning and providing feedback. ${ }^{32}$ At the hospital level, local feedback was emphasized; however, there were no clear systematic ways for providing this feedback. ${ }^{17}$ At the national level, although the informants from the National Committee were adamant that they have been somewhat responsive by providing feedback and learning, informants from most other organizations had not seen feedback or learning provided to hospitals or shared at the national level for more than 10 years since the system was first implemented. It is essential to provide staff with feedback. ${ }^{33}$ It is therefore recommended that feedback be given from the central or regional level to the health care organizations. For each organization, it is also important to publish and analyze the data to highlight the development across multiple years. ${ }^{27}$ Additionally, feedback must reach the reporter, the target group such as work unit and also the wider community. ${ }^{34}$ Publishing data and sharing the analysis is a key function of reporting and learning system, especially at the national level.
Finally, despite some characteristics of incident reporting system being regulated, there was a dearth of understanding and a great deal of confusion about the system at almost all levels. It could be that informants are simply ignorant of the established policy or are insufficiently socialized into an effective practice of incident reporting. In the Indonesian context, socialization is a common way to introduce new values or knowledge into society. A robust infrastructure at local and national levels to protect reporters of incidents in a non-punitive environment also needs to be fostered.

\section{Conclusion}

Despite being in operations for more than 10 years, the incident reporting system in Indonesia has not adequately adhered to the WHO characteristics for a successful reporting system. The lack of understanding and a great deal of confusion were found almost at all levels of its implementation. There is a pressing need for the Indonesian Government to improve the system, by putting more effort into socializing the regulations especially at provincial and district or city levels, and by creating a robust infrastructure at all levels to support the incident reporting.

At the participating organizations, the informants were those who directly led, or at least involved in, the patient safety program. They were chosen because of their extensive experience and knowledge of the incident reporting system and were therefore relatively senior. Nevertheless, we believe that the perspective of frontline staff is indeed as important as that of the informants involved in this study, and we have subsequently planned to include the frontline staff in our future research, thus making it more inclusive and comprehensive. It is envisaged that this will be part of our proposed next-generation incident reporting system whose features incorporate those that are well established in other countries. Nevertheless, we are mindful that our recommendations need to be aligned with the Indonesian government's policy and relevant regulations.

\section{Acknowledgment}

We would like to thank the Education and Culture Attaché of the Embassy of the Republic of Indonesia in London for the support in finalizing the manuscript.

\section{Disclosure}

The authors report no conflicts of interest in this work. 


\section{References}

1. Stavropoulou C, Doherty C, Tosey P. How effective are incident-reporting systems for improving patient safety? A systematic literature review. Milbank Q. 2015;93(4):826-866. doi:10.1111/1468-0009.12166

2. Tingle J. Improving the national reporting and learning system and responses to it. $B r J$ Nurs. 2018;27(5):274-275. doi:10.12968/ bjon.2018.27.5.274

3. Malaysia MOH. (2017). Guidelines on implementation - incident reporting and learning system 2.0 for ministry of health hospitals Available from: http://hus.moh.gov.my/bm/wp-content/uploads/2017/ 12/02.Layout-Buku-Incident-Reporting-2.0-28new29.pdf. Accessed January 24, 2019.

4. Lin CC, Shih CL, Liao HH, Wung CH. Learning from Taiwan patient-safety reporting system. Int J Med Inform. 2012;81(12):834 841. doi:10.1016/j.ijmedinf.2012.08.007

5. Doupi P. National reporting systems for patient safety incidents: a review of the situation in Europe. Persephone Doupi and National Institute for Health and Welfare; 2009. Available from: https://thl.fi/documents/10531/ 104907/Report\%202009\%2013.pdf. Accessed January 18, 2019.

6. Gong Y, Kang H, Wu X, Hua L. Enhancing patient safety event reporting. App Clin Inf. 2017;8(03):893-909. doi:10.4338/ACI-2016-02-R-0023

7. World Health Organization. World Alliance for Patient Safety: WHO Draft Guidelines for Adverse Event Reporting and Learning Systems. From Information to Action; 2005. Geneva:World Health Organization. Available from: https://www.jeder-fehler-zaehlt.de/lit/ further/Reporting_Guidelines.pdf. Accessed January 12, 2019.

8. Runciman W, Hibbert P, Thomson R, Van Der Schaaf T, Sherman H, Lewalle $\mathrm{P}$. Towards an international classification for patient safety: key concepts and terms. Int J Qual Health Care. 2009;21(1):18-26. doi:10.1093/intqhe/mzn057

9. WHO. Surgical safety checklist. 2009. Available from: https://www.who. int/patientsafety/topics/safe-surgery/checklist/en/. Accessed November 5, 2019.

10. WHO. WHO safe childbirth check list. 2015. Available from: https:// www.who.int/patientsafety/topics/safe-childbirth/childbirth-checklist/ en. Accessed November 5, 2019.

11. Indonesian Ministry of Health. Pedoman Nasional Keselamatan Pasien Rumah Sakit. [National Guidelines for Hospital Patient Safety]. Jakarta: Bakti Husada; 2015.

12. Hospital Patient Safety Committee. Pedoman Pelaporan Insiden Keselamatan Pasien [The Guidelines for Patient Safety Incident Reporting]. Jakarta: Bakti Husada; 2015.

13. Indonesian Ministry of Health. Hospital Act no. 44. 2009.

14. Indonesian Ministry of Health. Regulation of the Minister of Health of the Republic of Indonesia No. 11 year 2017 about patient safety. 2017.

15. Ekayani NP, Wardhani V, Rachmi AT. Nurses' intention and behavior in reporting adverse event: application of theory of planned behavior Natl Public Health J. 2017;11(3):138-144.

16. Hastuti SO. Penerapan budaya keselamatan pasien sebagai upaya pencegahan kejadian tidak diinginkan. [Implementation of patient safety culture as an effort to prevent adverse event] [dissertation]. Yogyakarta: Aisyiah University; 2013.

17. Dhamanti I, Leggat S, Barraclough S, Utarini A, Liao S. What can Indonesia learn from Taiwan's successful patient-safety reporting system? In: Shih YC, Liang SFM, editors. Bridging Research and Good Practices Towards Patient Welfare. Proceedings of the 4th International Conference on Healthcare Ergonomics and Patient Safety. June 23-26, 2014; Taipei, Taiwan: Taylor \& Francis; 2015:37-45.

18. Iskandar H, Maksum H, Nafisah N. Faktor Penyebab Penurunan Pelaporan Insiden Keselamatan Pasien Rumah Sakit [Factors causing the decrease of patient safety incident reported in hospital]. Jurnal Kedokteran Brawijaya. 2014;28(1):72-77. doi:10.21776/ub.jkb
19. Gusman Y. Evaluasi pelaporan eksternal insiden keselamatan pasien [External reporting of hospital patient safety incident and its evaluation]. Paper presented at the Hospital Patient Safety Workshop in South Kalimantan Province; 2017; Banjarmasin.

20. Terry G, Hayfield N, Clarke V, Braun V. Thematic analysis. In: Willig C, Rogers WS, editors. The Sage Handbook of Qualitative Research in Psychology. Vol. 26. 2017:17-37.

21. Dixon-Woods M, Agarwal S, Jones D, Young B, Sutton A. Synthesising qualitative and quantitative evidence: a review of possible methods. J Health Serv Res Policy. 2005;10(1):45-53. doi:10.1177/135581960501000110

22. Syam NS. Implementasi Budaya Keselamatan Pasien oleh Perawat di Rumah Sakit Ibnu Sina Makassar. [Implementation of patient safety culture by nurses at Ibnu Sina Hospital Makassar]. Jurnal Fakultas Kesehatan Masyarakat. 2017;11(2):169-174.

23. Iriviranty A, Ayuningtyas D, Misnaniarti M. Evaluation of patient safety culture and organizational culture as a step in patient safety improvement in a hospital in Jakarta, Indonesia. Patient Saf Qual Improv. 2016;4(3):394-399.

24. Wijaya AS, Dewi A. Analisis Budaya Keselamatan Pasien Di RSU PKU Muhammadiyah Bantul [Analysis on patient safety culture at RSU PKU Muhammadiyah, Bantul]. J Medicoeticolegal Manaj Rumah Sakit. 2015;4(1):1-9.

25. Gunawan G, Harijanto H, Harijanto T. Analisis Rendahnya Laporan Insiden Keselamatan Pasien di Rumah Sakit. [Analysis on low patient safety incident reporting in hospital]. Jurnal Kedokteran Brawijaya. 2015;28(2):206-213. doi:10.21776/ub.jkb

26. Anggraeni D, Azzuhri M. Pengaruh Budaya Keselamatan Pasien terhadap Sikap Melaporkan Insiden pada Perawat di Instalasi Rawat Inap Rumah Sakit Tk. II dr. Soepraoen [Effect of patient safety culture on attitudes to reporting incidents on nurses in inpatient unit at Dr. Soepraoen hospital]. J Aplikasi Manaj. 2016;14(2):309-321.

27. European Commission. Key findings and recommendations on Reporting and learning systems for patient safety incidents across Europe. European Commission; 2014. Available from: http://buonepratiche.agenas.it/docu ments/More/8.pdf. Accessed January 25, 2019.

28. Mahendradhata Y, Trisnantoro L, Listyadewi S, et al. The Republic of Indonesia Health System Review. Health Systems in Transition. India: World Health Organization; 2017. Available from: https://apps.who. int/iris/bitstream/handle/10665/254716/9789290225164-eng.pdf;jses sionid $=$ C37520FE543B4AB26CAC17A48D71CA78? sequence $=1$. Accessed November 5, 2019.

29. Haxby E, Shuldham C. How to undertake a root cause analysis investigation to improve patient safety. Nurs Stand. 2018;32 (20):41-46. doi:10.7748/ns.2018.e10859

30. Tewari A, Sinha A. Critical incident reporting: why should we bother? J Anaesthesiol Clin Pharmacol. 2013;29(2):147-148. doi:10.4103/0970-9185.111648

31. Holden RJ, Karsh B-T. A review of medical error reporting system design considerations and a proposed cross-level systems research framework. Hum Factors. 2007;49:257-276. doi:10.1518/ $001872007 \mathrm{X} 312487$

32. Holmström AR, Airaksinen M, Weiss M, Wuliji T, Chan XH, Laaksonen R. National and local medication error reporting systems -a survey of practices in 16 countries. J Patient Saf. 2012;8(4):165176. doi:10.1097/PTS.0b013e3182676cf3

33. Anderson JE, Kodate N, Walters R, Dodds A. Can incident reporting improve safety? Healthcare practitioners' views of the effectiveness of incident reporting. Int J Qual Health Care. 2013;25(2):141-150. doi:10.1093/intqhe/mzs081

34. Klemp K, Zwart D, Hansen J, et al. A safety incident reporting system for primary care. A systematic literature review and consensus procedure by the LINNEAUS collaboration on patient safety in primary care. Eur J Gen Pract. 2015;21(Suppl):39-44. doi:10.3109/ 13814788.2015.1043728 


\section{Publish your work in this journal}

Risk Management and Healthcare Policy is an international, peerreviewed, open access journal focusing on all aspects of public health, policy, and preventative measures to promote good health and improve morbidity and mortality in the population. The journal welcomes submitted papers covering original research, basic science, clinical \& epidemiological studies, reviews and evaluations, guidelines, expert opinion and commentary, case reports and extended reports. The manuscript management system is completely online and includes a very quick and fair peer-review system, which is all easy to use. Visit http://www.dovepress.com/testimonials.php to read real quotes from published authors.

Submit your manuscript here: https://www.dovepress.com/risk-management-and-healthcare-policy-journal 